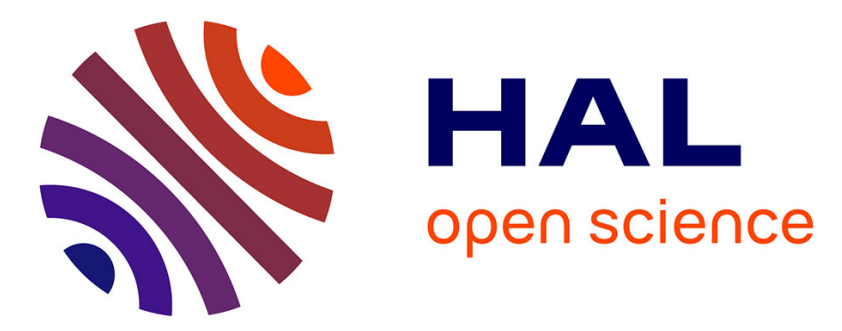

\title{
CORRELATION BETWEEN MICROSTRUCTURE OF NiO GRAIN-BOUNDARIES AND INTERGRANULAR DIFFUSION
}

\author{
M. Déchamps, A. Revcolevschi, Franck Barbier
}

\section{- To cite this version:}

M. Déchamps, A. Revcolevschi, Franck Barbier. CORRELATION BETWEEN MICROSTRUCTURE OF NiO GRAIN-BOUNDARIES AND INTERGRANULAR DIFFUSION. Journal de Physique Colloques, 1986, 47 (C1), pp.C1-309-C1-313. 10.1051/jphyscol:1986145 • jpa-00225575

HAL Id: jpa-00225575

https://hal.science/jpa-00225575

Submitted on 1 Jan 1986

HAL is a multi-disciplinary open access archive for the deposit and dissemination of scientific research documents, whether they are published or not. The documents may come from teaching and research institutions in France or abroad, or from public or private research centers.
L'archive ouverte pluridisciplinaire HAL, est destinée au dépôt et à la diffusion de documents scientifiques de niveau recherche, publiés ou non, émanant des établissements d'enseignement et de recherche français ou étrangers, des laboratoires publics ou privés. 


\title{
CORRELATION BETWEEN MICROSTRUCTURE OF NIO GRAIN-BOUNDARIES AND INTERGRANULAR DIFFUSION
}

\author{
M. DÉCHAMPS, A. REVCOLEVSCHI and F. BARBIER \\ Laboratoire de Chimie Appliquée, Bât. 414, Université \\ Paris-Sud, F-91405 orsay Cedex, France
}

\begin{abstract}
Résumé - Une diffusion intergranulaire préférentie]le de $\mathrm{Ni}$ et de $\mathrm{Co}$ a été signaTée dans de 1'oxyde de nickel polycristallin obtenu par oxydation thermique du nickel. Ces résultats ne sont pas confirmês sur du NiO obtenu par d'autres procēdés. La structure des joints est sans doute responsable de la diffërence de comportement.
\end{abstract}

Abstract - An enhanced intergranular diffusion of $\mathrm{Ni}$ and $\mathrm{Co}$ was observed in polycrystalline NiO prepared by thermal oxidation of nickel. These results are not confirmed in nickel oxide prepared by other methods. The structure of the grain-boundaries is believed to be responsible for this different behaviour.

\section{I - INTRODUCTION}

An enhanced intergranular diffusion of $\mathrm{Ni}$ and $\mathrm{Co}$ has been observed in the temperature range $500-800^{\circ} \mathrm{C}$ in nickel oxide samples prepared by thermal oxidation of nickel at $1100^{\circ} \mathrm{C} / 1 /$. This result, one of the few obtained on non-metallic materials, is not surprising since it is well accepted that diffusion proceeds more rapidly along grainboundaries (GB's) than through the lattice because, in particular, of the atomic jump frequency much greater than in the lattice $/ 2-5 /$. Numerous experiments, mainty carried out on metals, support this opinion and one frequently finds that grainboundary diffusion coefficients $D^{\prime}$ are several orders of magnitude greater than the corresponding lattice diffusion coefficients D /6\%. It is also well accepted that the dislocation structure of the GB's, that is, the type of dislocation (edge or screw), its dissociation, and its possible spreading, can influence the boundary diffusivity. To illustrate this point, one of the most fruitful models remains the pipe mechanism of diffusion of Turnbul1 and Hoffman based on the dislocation description of sub grain-boundaries (SGB's) $/ 7,8 \%$. The model predicts an influence of the misorientation between adjacent crystals as well as of the type of dislocation on the diffusion process; it also predicts an anisotropy of the intergranular diffusion.

Within this frame we have tried to refine the statistical results previously obtained on polycrystalline $\mathrm{NiO}$ (called hereafter "oxidized $\mathrm{Ni}$ ") by considering intergranular diffusion experiments on well defined GB's. This led us to carry out a large number of experiments on various $\langle 011\rangle$ or $\langle 001\rangle$ tilt axis bicrystalline samples grown from the melt ( $f$ lame fusion technique), which indicated no preferential grain boundary diffusion with respect to lattice diffusion. In order to explain these contradictory results a statistical study of the grain boundary features was performed by transmission electron microscopy. The orientation relationships, the coincidence index, the orientation texture of the GB' planes and their detailed microgeometry as well as the oxidation texture, when necessary, were studied in the bicrystals grown from the melt and in the "oxidized $\mathrm{Ni}$ ". The resulting data were compared with those determined on well annealed $\mathrm{NiO}$ specimen. As a result it appears that the nickel oxide obtained by oxidation is far from thermodynamic equilibrium and it is believed that this may be the origin of the difference in diffusional behaviour. 


\section{II - ORIGIN OF THE SAMPLES UNDER STUDY}

The origin and characteristics of the three types of materials which were studied are described elsewhere $/ 9 /$. Let us remind briefly what they are :

- "1100 $\mathrm{C}$ oxidized $\mathrm{Ni}$ " obtained by oxidizing a $30 \mu \mathrm{m}$ thick nickel foil at $1100^{\circ} \mathrm{C}$ (this polycrystalline material was provided by Atkinson who observed on it an enhanced intergranular diffusion /1/). According to the authors publications the total amount of metallic impurities contained into the original nickel is between 100 and 1200 p.p.m.

- " $1300^{\circ} \mathrm{C}$ oxidized $\mathrm{Ni}$ " obtained by oxidizing a $600 \mu \mathrm{m}$ thick foil at $1300^{\circ} \mathrm{C}$. This foil was then annealed during 240 hours at $1600^{\circ} \mathrm{C}$ leading to an "annealed NiO". The original nickel was a high purity metal purified by ion exchange. The amount of metalIic impurities, except $A 1$ and $S i$, was less than 5 p.p.m.

- crystals and bicrystals grown from the melt by the flame fusion technique /10/, which were previously investigated in order to determine their intergranular relative energy (fig. 1) /11/. These bicrystals were made from Johnson Matthey, grade 1 powder (metallic impurities < 20 p.p.m.). Activation analysis realized on Ni0 crystals after growing have confirmed the johnson Matthey analysis (except for A7 and $\mathrm{Si}$ which are difficult to analyse by activation in a $\mathrm{Ni}$ matrix).

During the numerous TEM observations and diffraction experiments not any precipitate was observed, either in the GB region or in the bulk. Moreover several bicrystals grown from the melt were broken under high vacuum ( $\simeq 10^{-8} \mathrm{~Pa}$ ) along $\mathrm{GB}$ 's and the latters analyzed by Auger spectrometry. The resulting analysis showed that the GB's in the bicrystals were free from segregation.

Diffusion experiments were carried out on the three types of materials (by Atkinson et a1. in the first case) together with extensive geometrical and morphological studies performed by TEM.

\section{II - DIFFUSION STUDY RESULTS}

As shown in fig. 1, the relative energy of the two series of symmetrical GB's is strongly dependent on misorientation, especially in the case of $\langle 011\rangle$ tilt boundaries for which three cusps were evidenced, corresponding to $\{221\},\{111\}$ and $\{311\}$ boundary planes (the respective coincidence indices $\Sigma$ are 9,3 and 11$)^{1}\left({ }^{1}\right)$. Although the absolute value of the intergranular energy remains unknown, the experimental evidence of the cusps is well estabiished and a cautious examination of the experimental conditions showed that the cusps correspond to GB energy minima. Now, Herbeuval et a1., in particular, have shown on aluminium $<011>$ tilt GB's that there exists a close
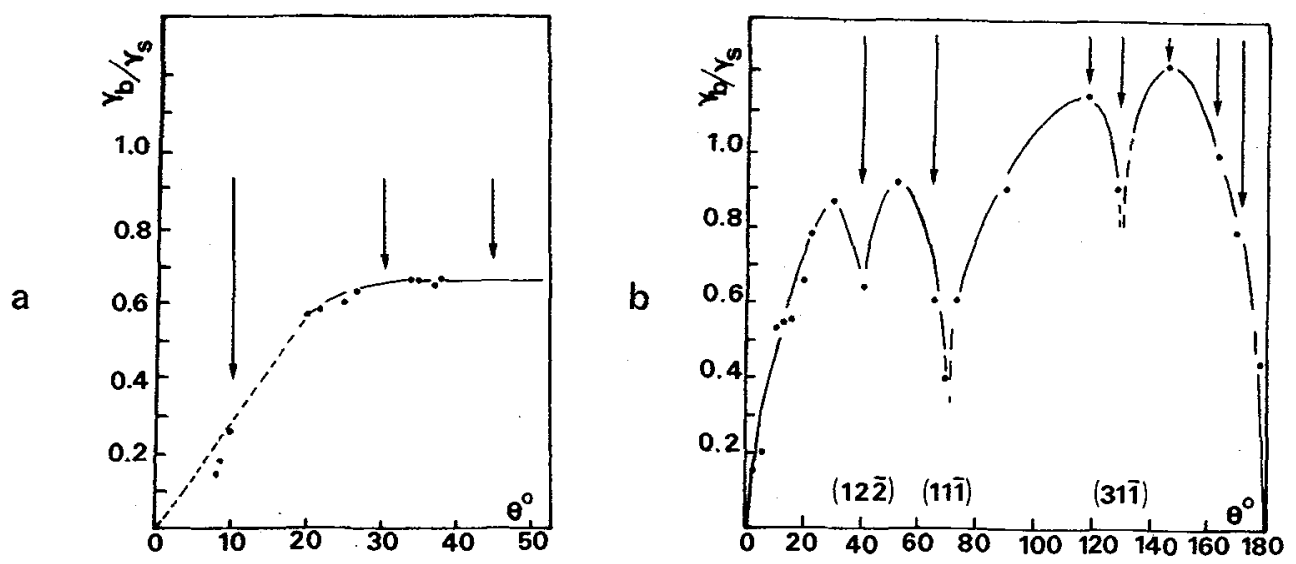

Fig. 1 - Influence of the misorientation $\theta$ upon the relative energy of [001] (a) and [011] (b) symmetric tilt grain boundaries at $1520^{\circ} \mathrm{C} / 11 \% \gamma_{b}$ is the GB energy and $\gamma_{s}$ is the surface energy. The low energy boundaries correspond to SGB's and to the (122), (11i) and (311) GB planes. The symmetrical tilt boundaries which were used for diffusion experiments are indicated by arrows. 
relationship between the energy of $a G B$ and the corresponding intergranular diffusion coefficient $D^{\prime} / 12 /$. By analogy we thought that the $\langle 011\rangle G B^{\prime}$ 's of our NiO samples were well suited for a verification of a similar energy-diffusion correlation in an ionic material. Several misorientations, indicated by arrows in fig. 1 and corresponding either to high energy misorientations, or to low energy misorientations, were selected. In the first case, it was expected to observe an important intergranular diffusion (the intergranular diffusion coefficient of $\mathrm{Ni}$ determined on "1100 oxidized $\mathrm{Ni} "\left(\mathrm{P}_{\mathrm{O}_{2}}=1 \mathrm{~atm}\right.$ ) is $D^{\prime} \delta=3 \cdot 10^{-8} \exp -(1.78(\mathrm{eV}) / \mathrm{kT})$, i.e. $D^{\prime} / D \sim 10^{6}$, if we assume as Atkinson for the $\mathrm{GB}$ width $\delta \simeq 7 \AA / 1 \%$. In the second case, corresponding to CSL misorientations of small misfit between adjacent grains, no diffusion or very limited preferential $G B$ diffusion was expected to be observed ( 3 ) $/ 13 /$.

Two types of diffusion experiments were undertaken : Self-diffusion using ${ }^{63} \mathrm{Ni}$ (quantitative experiments were carried out by abrasion and counting of the $\beta$ activity of the samples ; qualitative experiments used auto-radiography), and hetero-diffusion of homo-valent cobalt (quantitative measurements were made using the electron microprobe technique). No enhanced self-diffusion or hetero-diffusion were detected at the GB's. In order to complete our information, additional $\mathrm{Ni}$ self-diffusion experiments were undertaken on polycrystalline "1300 oxidized $\mathrm{Ni}$ " samples, after polishing the as-oxidized surface, but before further high temperature annealing. Again, no preferential $G B$ diffusion was evidenced on these polycrystalline samples.

\section{IV - GRAIN BOUNDARY MICROSTRUCTURE}

In order to find a possible explanation to these apparent diffusion discrepancies, the GB's were subjected to crystallographic characterization, morphological studies and dislocation structure determinations.

IV.1. Crystallographic description of the GB's : such a description includes, the 5 macrocospic parameters needed to define the orientation relationship existing between the adjacent crystals and the indexation of the GB plane in relation to both crystals $114 /$. This determination was carried out using the crystallographic data collected from TEM micrographs and diffraction patterns, according to methods detailed in severa 7 papers $/ 14-16 /$. Briefly the results can be summarized as follows (see ref. 9 and 14 for details) :

- Orientation relationships : these relations, described by a rotation $\theta$ around an axis R, were computed for each interface and the results used to look for a possible coincidence index $\Sigma$. In the "flame fusion crystals" some specimen are closely approximating low values of $\Sigma$, as indicated in fig. 1 . In the " $1100^{\circ} \mathrm{C}$ oxidized $\mathrm{Ni} "$ and in the "annealed NiO" a coincidence index (within the limit of $\Sigma \leqslant 41$ ) can be al loted to about $12 \%$ of the couples of crystals adjacent to each GB (2). However no preferential relationship appears, whatever the thermal treatment is.

- Orientation of the GB planes : this characteristic was determined for 113 couples of grains for the " $1100^{\circ} \mathrm{C}$ oxidized $\mathrm{Ni}$ " and for 23 couples for the "annealed $\mathrm{NiO}$ ". The results are reported on standard [001] stereographic triangles (fig. 2). These data are quite interesting because of the GB clearcut tendency, in both types of specimen to avoid the $\{011\}$ orientations defined with respect to one of the crystals, this tendency being strongly enhanced by annealing, since we do not observe GB pianes within $15^{\circ}$ of $(011)$. It must be emphasized that this cannot result from the texture which develops either during the oxidation, or the annealing processes $\left({ }^{3}\right)$. Hence, geometrical considerations, linked with the columnar oxidation growth of the grains cannot be evoked to explain the absence of $\{011\}$ planes.

(1) $-\Sigma$ is the ratio of the volume of the Coincidence Site Lattice (CSL) unit cell to that of the crystal lattice cell.

- The CSL misorientations are singular orientation relationships corresponding to a high density of sites common to both lattices, which form the CSL lattice. According to theory, the higher the density of common sites, the lower the energy of an interface passing through a low index CSL lattice plane.

$\left({ }^{2}\right)-12 \%$ instead of the previously reported $50 \%$ by ref. 14 . The disagreement is due to the erroneous method which was first used to determine the deviation of the bicrystals from the CSL coincidence misorientation $/ 21 \%$. 

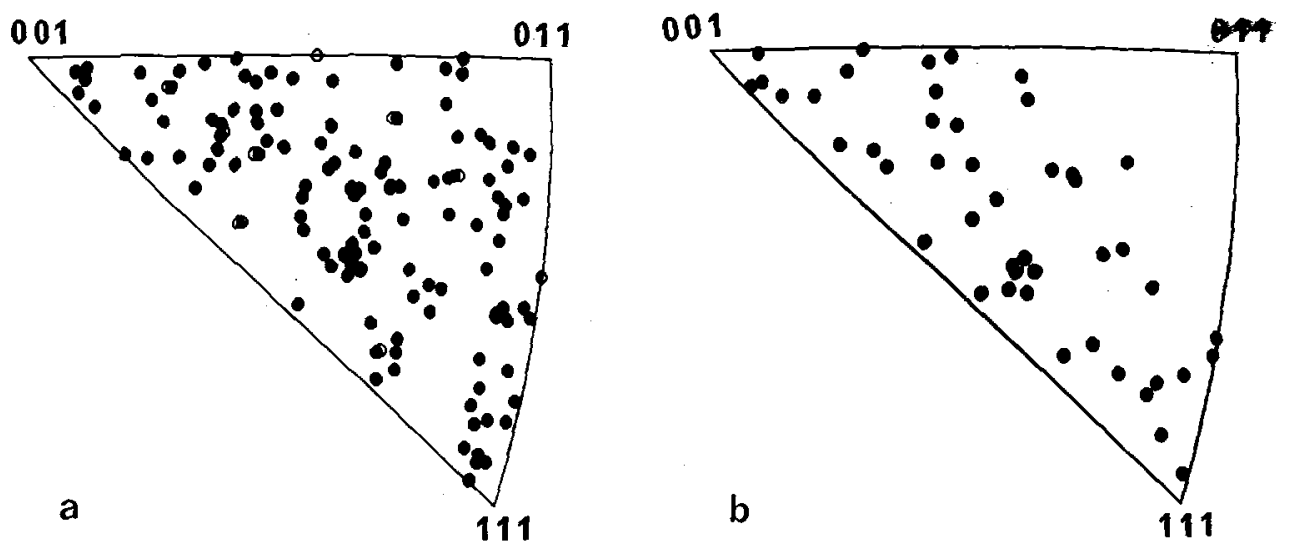

Fig. 2 - Distribution of the GB plane orientation in "oxidized NiO" (a) and "annealed $\mathrm{NiO}$ (b). The absence of $\{011\} \mathrm{GB}$ plane, already noticeable in (a) is strongly enhanced after annealing (b).

As a conclusion it seems that an interface corresponding to a high angle $G B$, close to a $\{011\}$ plane, indexed with respect to one of the adjacent crystals, is particularly unstable, as shown by the evolution of the distribution of the GB's during annealing. Although the reason of this tendency is not yet understood it appears clearly that the GB's, in the " $1100^{\circ} \mathrm{C}$ oxidized $\mathrm{Ni}$ ", are far from being in the equilibrium state.

IV.2. Grain boundary morphology : the morphology of the various examined interfaces depends on the origin of the NiO and on the thermal treatment to which it was subjected. Facetting does not occur in the high angle misorientation $G B$ 's, whatever the origin and the thermal treatment of the NiO is. Conversely, the morphology of the SGB's is strongly dependent on the "history" of the material. In the "1100' C oxidized Ni", SGB'S are not facetted, but in the "annealed $\mathrm{NiO}$ ", as well as in the flame fusion crystals, facets are systematically observed. They are mostly made of large portions of $\{011\}$ and $\{112\}$ planes and of $\{113\}$ and $\{122\}$ ledges. It can be noted that these latter planes correspond to cusps in fig. 1.b, that is, to energetic minima of some GB's.

These observations can be interpreted as follows. A GB can be either plane (on a large scale), or facetted. Facetting has either a kinetic origin (e.g. when the GB is far from thermodynamical equilibrium, during a fast grain growth) or an energetic origin (e.g. When it is closely approximating an equilibrium state) $/ 17 \%$. Close to equilibrium, which occurs for example after a long annealing at high temperature ("annealed $\mathrm{Ni0"}$ ), a GB can reduce its surface energy by facetting along the lowest energy crystallographic planes compatible with its average orientation. Hence, the possible evolution of the morphology is another criterion which may suggest that GB's are not in an intrinsic structural equilibrium. However facetting will take place only if the surface energy of the new facets is low enough to compensate for the increased surface. This is the reason why high angle GB's do not facet easiTy.

\section{$V$ - CONCLUSION}

Data relative to intergranular diffusion studies in polycrystalline oxides are not in good agreement $/ 1,18 /$ and the mechanism of $G B$ diffusion is not yet well understood. Wuench and Wasilos /19/ and Osenbach and Stubican /20/, for example, suggest that enhanced diffusion of cations along GB's in. MgO may be attributed to impurity segregation at the boundary. The diffusion discrepancies could be explained in a similar way since the "1100 $\mathrm{C}$ oxidized $\mathrm{Ni}$ " is likely the less pure of the materials under investigation, though Atkinson et al. have pointed out that there was no precipitate at the GB's.

(3) - The sample texture, determined on a limited number of crystais by TEM, was shown after an additional X-Ray study, to be representative. 
However, the comparison of the characteristics of the GB's shows that the " $1100^{\circ} \mathrm{C}$ oxidized $\mathrm{Ni}$ " is far from equilibrium and conversely, the "annealed NiO" looks quite similar to the flame-fusion crystals, where the $G B^{\prime} s$ seem to be almost at eguilibrium. Since the properties of a $G B$ are closely related to its structure, it is not unreasonable to think that the preferential $\mathrm{GB}$ diffusion observed in the $11100^{\circ} \mathrm{C}$ oxidized $\mathrm{Ni}^{\prime \prime}$ is Targely due to the fact that the grain boundaries are far from eauilibrium.

\section{REFERENCES}

/1/ Atkinson A. and Taylor R.E., Phil. Mag. A.43 (1981) 979.

Atkinson A. and Taylor R.E., Phil. Mag. A.45 (1982) 583.

12/ Peterson N.L., Grain Boundary Structure and Kinetics, p. 209, ASM (1980).

/3/ Ballufi R.W., Phys. Stat. Sol. 42 (1972) 11.

14/ Gleiter H. and Chaimers B., Prog. Mater. Sc. 16 (1972) 101.

15/ Martin G. and Perailion B., J. de Physique, CoTloque C4 (1975) 165.

16/ Martin G. and Peraillon B., Grain Boundary Structure and Kinetics, p. 239, ASM (1980).

/7/ Turnbu11 D. and Hoffman R.E., Acta Meta11. 2 (1954) 419.

/8/ Atkinson A. and Leclaire A.D. , Dislocations 1984, p. 253 , Ed. by C.N.R.S. (1984).

19/ Marrouche A., Barbier F. and Déchamps M., Surface Sc., in press.

110/ Dhalenne G., Revcolevschi A. and Gervais A., J. Crystal Growth 44 (1978) 297.

/11/ Dhalenne G., Déchamps M. and Revcolevschi A., Advances in Ceramícs 6 (1983) 139.

/12/ Herbeuval T. and Biscondi M., Canad. Metal1. Quartely 13 (1974) 171 .

/13/ Sutton A.P., Internationa? Metals Review 29 (1984) 377.

114/ Déchamps M.', Marrouche A., Revcolevschi A. and Barbier F., J. de Physique, C4. 46 (1985) 435 .

715/ Sharko R., Thèse, Paris (1983).

116/ Fontaine C. and Rocher A., J. Microsc. Electron. 4 (1979) 19.

117/ Bishop G.H., Hartt W.H. and Bruggman G.A., Acta Metal1. 19 (1971) 37.

/18/ Chen W.K. and Peterson N.L., J. Amer. Ceram. Soc. 63 (1980) 566.

$/ 19 /$ Wuensch B.J. and Vasilos T., J. Amer. Ceram. Soc. 49 (1966) 433.

/20/ Osenbach J.W. and Stubican V.S., J. Amer. Ceram. Soc. 66 (1983) 191.

121/ Déchamps M., Barbier F, and Marrouche A., to be published. 